\title{
IS PREOPERATIVE OCCUPATION RELATED TO LONG-TERM PAIN IN PATIENTS OPERATED FOR LUMBAR DISC HERNIATION?
}

\author{
Daniel Benzecry Almeida, Paola Hesse Poletto, Jerônimo Buzetti Milano, \\ André Giacomelli Leal, Ricardo Ramina
}

\begin{abstract}
Lumbar disc herniation (LDH) is a common cause of back and sciatic pain. When clinical treatment fails, surgery may be indicated in selected patients. Although surgery is effective in most cases, some of these patients may have a poor outcome. Different factors may influence these results and poor adaptation at work is one well-known cause of treatment failure. This study examines 350 patients on longterm follow-up after surgery for first-time LDH. The relationship was analyzed between occupation before surgery and outcome (maintenance of lumbar and leg pain, satisfaction with the surgical treatment and return to work). The preoperative occupation (employed in public or private services, autonomous, unemployed, housewife, retired or student) and the exertion at work were analyzed as prognostic factors for different clinical outcomes. Although unemployed people had higher numerical analog scale for lumbar pain and retired patients had a higher leg pain, this difference was not statistically significant. Retired people were significantly less satisfied with the surgical result. Higher exertion at work showed a statistically insignificant higher level of pain and lower degree of satisfaction. The authors conclude that preoperative occupation was not a statistically significant factor in this series of patients.
\end{abstract}

KEY WORDS: lumbar disc herniation, occupation, failed back syndrome, outcome, discectomy.

\section{Cirurgia de hérnia de disco lombar: existe relação entre a profissão e a persistência de dor?}

\begin{abstract}
RESUMO - A hérnia de disco lombar (HDL) é uma causa comum de dor lombar e ciática. Quando o tratamento clínico não oferece melhora dos sintomas, a cirurgia pode ser proposta em casos selecionados. Apesar de ser efetiva, uma pequena, porém significativa parcela dos pacientes operados podem não melhorar. Diversos fatores podem influenciar tais resultados. A insatisfação no ambiente de trabalho é relacionada com um maior índice de maus resultados. Neste estudo, 350 pacientes no pós-operatório tardio da primeira cirurgia de HDL foram estudados, analisando a possível relação entre tipo de profissão antes da cirurgia e evolução clínica (persistência de dor lombar e em membro inferior, satisfação com a cirurgia e retorno ao trabalho). Os pacientes foram classificados quanto à profissão em empregados públicos, empregados em órgãos privados, autônomos, desempregados, donas de casa, aposentados e estudantes. Também o grau de esforço no ambiente de trabalho foi analisado como fator prognóstico. Os desempregados relataram índices de dor lombar maiores e os aposentados tiveram maiores índices de dor irradiada, apesar de que estatisticamente os valores não foram significativos. Os aposentados ficaram significativamente menos satisfeitos com o tratamento no longo prazo. Um maior esforço no ambiente de trabalho não se correlacionou estatisticamente com o grau de dor e satisfação. Concluimos que o tipo de profissão não foi fator estatisticamente significativo na evolução destes pacientes. Os aposentados tiveram menor grau de satisfação com o procedimento cirúrgico.
\end{abstract}

PALAVRAS-CHAVE: hérnia de disco lombar, profissão, dor lombar, dor irradiada, dor ciática.

Lumbar disc herniations (LDH) are abnormal displacements of the intervertebral disc. When directed backwards through the spinal canal, they can compress neural structures, triggering an inflammatory reaction involving the dural sac and spinal root $^{1-3}$. LDHs are common causes of lumbar and sciatic pain, causing disability and economic losses worldwide ${ }^{4}$.
The treatment is initially conservative in most cases, including a rehabilitation program and medications such as antiinflammatories, muscle relaxants and opioids ${ }^{5,6}$. Despite correct clinical treatment, the painful symptoms will not improve for a significant number of patients. Surgery is usually indicated when there is a clear correlation between LDH and

Neurosurgery, Instituto de Neurologia de Curitiba, Curitiba, Brazil.

Received 22 January 2007, received in final form 11 April 2007. Accepted 21 May 2007. 
the persistence of pain, after appropriate clinical and radiological investigation.

When rigorous selection criteria are used and when a skilled surgical team performs the operation, the postoperative results are often good. Nevertheless, a significant number of patients don't get better. Those patients, known as failed-back surgery syndrome, may experience persistent pain due to multiple factors such as additional clinical disorders, technical problems, instability, poor indication criteria, excessive fibrosis and psychosocial disturbances ${ }^{7,8}$.

Beyond physical findings and technical procedures, psychological and occupational disturbances relate to a poorer outcome. There is an increasing consensus that conflicts in the professional environment are related to a worse prognosis after LDH surgery $^{9,10}$.

This study analyzes the results of patients operated on for LDH, focusing on the preoperative occupational status (POS). The aim of this study was to establish any possible correlation between POS and long-term follow-up. The persistence of lumbar and leg pain, the need for further treatments and satisfaction with the surgical results were analyzed as outcomes.

\section{METHOD}

Study population and designs - The study population consisted of patients with a diagnosis of LDH operated on in our Institution from August 1992 until August 2002 were evaluated after ethical analysis and approval. Surgery was performed with similar microneurosurgical operative technique. For statistical analysis, only those patients with longterm follow-up (more than 3 years after surgery) and complete data were analyzed.

Exclusion criteria - Patients operated on in the lumbar region by other spine surgeons were excluded, as well as patients requiring fusion at the first operation and those with additional spinal disorders, such as spinal stenosis, spondylolisthesis, instability or fractures.

Data collection - The preoperative data were retrospectively analyzed. A letter explaining the goals of the study and a questionnaire was sent to each patient. The questions could be answered over the telephone or sent by fax. The more specific questions were: the patient's age, occupation before and after surgery, details of his/her employment such as if it was in a public or private institution, whether the patient was an employee or not, the physical effort exerted at work, any disabilities in occupational and social life, pain analog scale for lumbar and leg pain and the need for further treatment such as other surgeries.

The main indication for surgery in these patients was the persistence of lumbar and sciatic pain and clinical and radiological signs of radicular involvement with inadequate relief after a period of at least 45 days of clinical treatment. A confirmation of LDH by computerized tomography (before 1993) and magnetic resonance (after 1993) was mandatory in every case, and the image had to show either a herniation or an extrusion of the disc through the spinal canal with signs of neural compression.

Outcome evaluation - The patients were classified according to their preoperative occupation as: 1) employee in a public institution; 2) employee at a private service; 3 ) employee in both public and private institutions; 4) autonomous; 5) housewife; 6) unemployed; 7) retired; 8) student.

The patients also classified their physical effort at work before surgery as: 1) sedentary or minimal; 2) moderate or 3) heavy.

The patients were asked to evaluate their pain in both in the lumbar and the leg region using a numerical analog scale (NAS), with values from 0 to 10 , with 0 representing no pain and 10 the worst pain imaginable ${ }^{11}$.

In the same way, the patients were asked to express their degree of satisfaction with the surgical treatment, choosing one of five possibilities: a) strongly satisfied; b) moderately satisfied; c) little satisfied; $d$ ) unsatisfied; or e) strongly unsatisfied. For statistical analysis the first two options were grouped as satisfied and the last three categories were considered as unsatisfied.

Return to work - Patients were asked about their return to work after the operation, choosing from five options: a) normal with no disability; b) return to work with little disability; c) return to work with moderate disability; d) return to work with strong disability and e) no return to work. For statistical analysis, the first two were classified as satisfactory return to work, while the remaining three were classified as unsatisfactory return to work.

Operative technique - A 4-6 cm lumbar midline incision was carried out over the corresponding spinal level. The paravertebral muscles were retracted laterally on the side where symptoms occurred, followed by a hemilaminectomy large enough to expose the dura mater, spinal root and the entire disc herniation. A surgical microscope was used afterwards. The ligamentum flavum was opened with a scalpel, the dural sac and root were retracted medially and the discectomy was done by opening the posterior longitudinal ligament. After disc removal, there was the concern of hemostasis, but no hemostatic or anti-fibrotic material was left.

Statistical analysis - Data are reported as mean \pm standard deviation or as frequency (percent). After having evaluated the homogeneity of variance (Cochrane test) the normal distribution of each group of data (Shapiro Wilks test), an ANCOVA was performed to determine the differences between groups defined by nominal variables. The time between surgery and evaluation was considered as a co-variable, and the least significance difference (LSD) test was used to compare two groups. Comparisons between two groups for nominal variables were made with Fisher's exact test. Statistical significance was accepted for $p<0.05$. 


\section{RESULTS}

Number of patients - A total of 494 patients were operated on for LDH from 1992 to 2002 in our Institution. For 136 of these patients a complete dataset was not available due to changes in address and phone numbers. During the long-term follow-up, six patients died due to causes other than the surgery and two were disabled by dementia. A total of 350 patients had complete dataset and were considered as the sample group for this study.

Demographics - 350 patients were included in this study. The group consisted of 183 women and 167 men, with a mean age of 43.1 years (range 14-77 years old). The lumbar level operated on was L2-L3 in 4 (1.1\%); L3-L4 in 12 (3.4\%); L4-L5 in $132(37.7 \%)$; L5-S1 in 166 (47.4\%). More than one level was operated on for 36 patients $(10.3 \%)$. The side of the surgery was the left for 178 patients $(50.8 \%)$; the right for $151(43.1 \%)$ and bilateral for 21 (6\%). Follow-up time ranged from 3 to 15 years (mean 5.2 years).

Occupational status before surgery - There were 91 employees in public service (26\%); 96 employees in private service (27.4\%); 4 employees part time in public and part time in private service $(1.1 \%) ; 89$ autonomous (25.4\%); 40 housewives (11.4\%); 4 unemployed $(1.1 \%) ; 19$ retired $(5.4 \%)$ and 7 students $(2 \%)$.
According to the patients' questionnaire answers, the physical exertion at work for those working is shown in Table 1.

Occupation versus lumbar and leg pain - Mean NAS for each occupation group is shown in Table 2. Unemployed people had the worst lumbar pain NAS while the retired group had the worst leg pain NAS. On the other hand, students had the better lumbar and leg NAS. The difference between those groups was not statistically significant, either for lumbar pain $(p=0.2930)$ or for leg pain $(p=0.3008)$.

Occupation versus degree of satisfaction - The relationship between occupation before surgery and degree of satisfaction at late follow-up is shown in Table 3. Housewives had the best degree of satisfaction $(100 \%)$, while retired people had the worst (63.2\% satisfied). There was a statistically significant difference between the retired group and those employed in private service $(p=0.0263)$; employed in public service $(p=0.0035)$; autonomous $(p=0.0007)$ and housewives $(p=0.0001)$.

Occupation versus return to work - The relationship between the occupation before surgery and return to work was analyzed only for the working group (i.e. public, private, both or autonomous). All

Table 1. Physical exertion at work based on patients' own evaluation.

\begin{tabular}{lccc}
\hline & Minimal & Moderate & Heavy \\
\hline Public employee & $64(70.3 \%)$ & $24(26.4 \%)$ & $3(3.3 \%)$ \\
Private employee & $64(66.6 \%)$ & $28(29.2 \%)$ & $4(4.2 \%)$ \\
Public + private & $1(25 \%)$ & $3(75 \%)$ & 0 \\
Autonomous & $60(67.4 \%)$ & $24(27 \%)$ & $5(5.6 \%)$ \\
Housewife & $18(45 \%)$ & $21(52.5 \%)$ & $1(2.5 \%)$ \\
\hline
\end{tabular}

Table 2. Lumbar and leg pain at late follow-up according to preoperative occupation.

\begin{tabular}{lccc}
\hline & Number & $\begin{array}{c}\text { NAS lumbar pain } \\
\text { (mean) }\end{array}$ & $\begin{array}{c}\text { NAS leg pain } \\
\text { (mean) }\end{array}$ \\
\hline Public & 91 & 2.98 & 2.65 \\
Private & 96 & 3.23 & 2.09 \\
Priv/ public & 4 & 2.25 & 2.50 \\
Autonomous & 89 & 2.72 & 2.15 \\
Housewife & 40 & 3.22 & 2.33 \\
Unemployed & 4 & 4.75 & 2.50 \\
Retired & 19 & 3.05 & 3.32 \\
Student & 7 & 0.57 & 0.14 \\
Total & 350 & 2.98 & 2.31 \\
\hline
\end{tabular}

NAS, numerical analog scale. 
Table 3. Degree of satisfaction with the surgical treatment on different occupations.

\begin{tabular}{lccc}
\hline & Number & Satisfied & Unsatisfied \\
\hline Public & 91 & $82(90.1 \%)$ & $9(9.9 \%)$ \\
Private & 96 & $82(85.4 \%)$ & $14(14.6 \%)$ \\
Priv/ public & 4 & $3(75 \%)$ & $1(25 \%)$ \\
Autonomous & 89 & $83(93.3 \%)$ & $6(6.7 \%)$ \\
Housewife & 40 & $40(100 \%)$ & 0 \\
Unemployed & 4 & $3(75 \%)$ & $1(25 \%)$ \\
Retired & 19 & $12(63.2 \%)$ & $7(36.8 \%)$ \\
Student & 7 & $6(85.7 \%)$ & $1(14.3 \%)$ \\
Total & 350 & $311(88.9 \%)$ & $39(11.1 \%)$ \\
\hline
\end{tabular}

Table 4. Workers' long-term return to work after surgery.

\begin{tabular}{lccc}
\hline & Number & Satisfactory & Unsatisfisfactory \\
\hline Public & 91 & $63(69.2 \%)$ & $28(30.8 \%)$ \\
Private & 96 & $68(70.8 \%)$ & $28(29.2 \%)$ \\
Priv/ public & 4 & $4(100 \%)$ & 0 \\
Autonomous & 89 & $70(79.6 \%)$ & $19(20.4 \%)$ \\
Total & 280 & $205(73.2 \%)$ & $75(26.8 \%)$ \\
\hline
\end{tabular}

workers in both private and public service had a satisfactory return to work, although the number of patients in this group was small. The autonomous group had the higher rate of return to work. There was no difference between workers in public or private service (Table 4).

Exertion at work versus pain and satisfaction - This topic was studied to confirm whether a worse prognosis was related to a higher effort at work. A higher effort at work before surgery related to higher pain, but this difference was not statistically significant either for lumbar $(p=0.1643)$ or leg pain $(p=0.1030)$.

In the same way, the possible relationship between effort at work and degree of satisfaction was analyzed. A lower degree of satisfaction was related with higher effort at work before surgery, but once again this relationship was not statistically significant.

Gender versus pain and satisfaction - Women had a mean NAS for lumbar pain higher than men (3.38 $x$ 2.54), a difference which was not statistically significant $(p=0.062)$. Nevertheless, leg pain in women was higher $(2.79 \times 1.79)$ with statistical significance $(p=$ 0.003 ). There was no statistical difference between satisfaction and gender $(p=0.12)$

Age versus pain and satisfaction - As a difference was found in retired patients, the authors analyzed the effect of age versus pain and degree of satisfaction. For lumbar pain, there was a small difference between age groups, but it was not statistically significant ( $p=0.077$ ). For leg pain, on the other hand, an older age related to a higher NAS score with a significance of $p=0.002$.

An older age was also related to a statistically significant worse degree of satisfaction $(p=0.0146)$.

\section{DISCUSSION}

Low back pain is a major problem in health services all around the world ${ }^{12}$, and it is usually related to disc degeneration ${ }^{13}$. Some risk factors have been studied such as mechanical stress to the spine ${ }^{14}$, night shift work, lack of sporting activities and cigarettesmoking $^{1,15}$. Lumbar disc herniation is a common cause of lumbar and sciatic pain. Surgical treatment may be indicated for a selected group of patients, when the conservative treatment is ineffective and there is clinical and radiological evidence of dural sac and spinal root compression ${ }^{16}$. In a review of randomized controlled trials, discectomy has shown considerable evidence of the relative effectiveness when compared with other methods such as chemonucleolysis and automated percutaneous discectomy ${ }^{17}$. This procedure is currently the third most frequent surgery in many countries, including the United States ${ }^{14,18}$.

When good selection criteria are used, postoperative results are usually rewarding, but even in skilled 
hands a significant number of patients (ranging from 10-30\%) may experience persistent lumbar and leg pain $^{19,20}$. This problem, usually described as failedback surgery syndrome, causes considerable economic and social losses worldwide ${ }^{21}$.

It is well known that different factors may be related to persistent pain. These factors include misdiagnosis, technical failure, new disc protrusion, bony compression, excessive fibrosis, facet syndrome, infection and instability ${ }^{7,22-24}$. In a retrospective study Osterman et al. ${ }^{25}$ found a risk of $25,1 \%$ of further spinal surgery in the first ten years of follow-up. The success of spine surgery decreases after repeated surgeries ${ }^{24 .}$

Gender is an uncertain prognostic factor. Fritsch ${ }^{19}$ found a significant influence of the patient's sex on the long-term follow-up, with $18 \%$ of male patients presenting a satisfactory long-term result in contrast to $32 \%$ of females. Other authors have argued against this result ${ }^{26,27}$. A negative influence of age on the outcome has been discussed, with inconclusive data ${ }^{27}$.

Psychological and occupational problems seem to play important roles ${ }^{2,28}$. For this reason, they should be a concern for spinal surgeons. Many prospective series have shown that psychological distress, depressive mood and somatization relate with persistence of lumbar pain ${ }^{8,29,30}$. Levy et al. ${ }^{31}$ used a three-question depression screener for lumbar disc herniation and spinal stenosis. A positive response was found in $38,4 \%$ of patients with LDH, and this was associated with poorer functional status and health-related quality of life, as well as higher symptom intensity. Anema et al. ${ }^{32}$ showed that medical management may be an obstacle for return to work in some cases.

Conversely, those patients with better job satisfaction have a significantly better outcome and earlier return to work ${ }^{21,33-35}$. Psychosocial aspects of health and work have a significantly larger impact on the return to work than more physical aspects of disability ${ }^{21}$. Significant associations have been shown between low-back pain and perceived inadequacy of income, dissatisfaction with work and poorer social class $^{35}$. Poorer outcomes are seen in patients' filing of workers' compensation claims ${ }^{26}$.

Schade et al. ${ }^{36}$ stated that the return to work was not influenced by clinical or radiological findings, but only by psychological factors and self evaluation of work (occupational mental stress). Hildebrandt et al. ${ }^{37}$ studied patients with low-back pain and demonstrated that a negative self-evaluation for predict- ing a return to work was related to a longer period out of work and an application for pension was significantly related to a low probability of a patient's return to work. Although this result was statistically insignificant, the authors also stated that patients with a low level of education or low professional status were less likely to return to work, a statement confirmed by other studies ${ }^{34}$. Pransky ${ }^{38}$ found that simply measuring return to work does not seem to capture the full range of work-related consequences from occupational back injuries, and he reinforced the importance of the timing of the return to work, occupational ergonomic risks and appropriate job changes. Prescription of work restriction, however, doesn't appear to influence either the recurrence of unspecific low back pain or the early return to work ${ }^{39}$.

In Brazil, some peculiar characteristics of workers may be distinct from different countries. The first is the high number of housewives, although this is progressively decreasing each year. The other difference is that employees in public service have tenure or the right of constancy at a job guaranteed by law. An employee at a public institution can only be fired if a serious problem can be proven. For this reason, it was important to know whether this could lead to different results when compared to private companies where there was no guarantee of keeping that job.

This study found that the unemployed group had higher lumbar pain, while retired people had higher leg pain. Although this difference was not statistically significant, it may reflect a tendency for these patients to have a worse prognosis, as has been stated by some authors ${ }^{40}$.

The degree of satisfaction after surgery was similar within the working group, with no difference if they were employees or autonomous. The retired group was significantly less satisfied. Additional analysis based on age demonstrated that older people had a lower degree of satisfaction. Probably, an explanation is that elderly people usually have additional spine abnormalities, systemic diseases and higher depression ${ }^{8,29}$.

In this study, $100 \%$ of housewives had a good/excellent degree of satisfaction, although their pain NAS was similar to other groups. So, in some cases, pain status and operative satisfaction were not always related.

Strenuous effort at the workplace before surgery was related to a higher level of pain and a lower degree of satisfaction after surgery, although this result 
was not statistically significant. In this study, as the level of exertion was determined by the patient himself, this subjective analysis could introduce a bias. Some authors have shown a correlation between effort at work and persistent low back pain ${ }^{41}$.

Graver et al. ${ }^{42}$ found that strenuous work activities were related to a lower frequency of return to work. In a subsequent paper, he found that physical fitness has no significant prognostic value ${ }^{27}$, reinforcing the concept that it is not the effort itself, but the patients' perception of it that may influence the outcome for return to work.

In conclusion, this retrospective study demonstrated no major relationship between occupational status and prognosis for patients undergoing lumbar disc surgery. Retired patients were statistically less satisfied, although their lumbar and leg pain showed only slightly higher pain measures. On the other hand, housewives had a better degree of satisfaction, while their mean NAS was similar. In this population, strenuous effort at work before surgery had a small and statistically insignificant influence on the outcome.

\section{REFERENCES}

1. Fogelholm RR, Alho AV. Smoking and intervertebral disc degeneration. Med Hypoth 2001;56:537-539.

2. Natvig B, Eriksen W, Bruusgaard D. Low back pain as a predictor of long-term work disability. Scand J Public Health 2002;30:288-292.

3. O'Donnell JL, O'Donnell AL. Prostaglandin E2 content in herniated lumbar disc disease. Spine 1996;21:1653-1656.

4. Berger A, Dukes EM, Oster G. Clinical characteristics and economic costs of patients with painful neuropathic disorders. J Pain 2004;5: 143-149.

5. Saal JA. Natural history and nonoperative treatment of lumbar disc herniation. Spine 1996;27:2538-2545.

6. Bernstein E, Carey TS, Garrett JM. The use of muscle relaxant medications in acute low back pain. Spine 2004;29:1346-1351.

7. Goupille P. Causes des echecs de la chirurgie discale. Rev Rhum (Ed Fr.) $1996 ; 63: 255-260$.

8. Pincus T, Burton K, Vogel S, et al. A systematic review of psychological factors as predictors of chronicity/disability in prospective cohorts of low back pain. Spine 2002;27:E109-E120.

9. Schultz IZ, Crook J, Meloche GR, et al. Psychological factors predictive of occupational low back disability; towards development of a return to work model. Pain 2004;107:77-85.

10. Geiss A, Rohleder N, Kirschbaum C, Steinbach K, Bauer HW, Anton F. Predicting the failure of disc surgery by a hypofunctional HPA axis: evidence from a prospective study on patients undergoing disc surgery. Pain 2005;114:104-117

11. Teixeira MJ, Pimenta CAM, Grossi SAA, Cruz DALM. Avaliação da dor: fundamentos teóricos e análise crítica. Rev Med (São Paulo) 1999; 78:85-114.

12. McKinnon ME, Vickers MR, Ruddock VM, et al. Community studies of the health service implications of low back pain. Spine 1997;22:21612166.

13. Porchet F, Wietlisbach V, Burnand B, et al. Relationship between severity of lumbar disc disease and disability scores in sciatica patients. Neurosurgery 2002;50:1253-1260.

14. Andersson GBJ. Epidemiology of low back pain. Acta Orthop Scand 1998;69(Suppl 281):S28-S31.

15. Elfering A, Semmer N, Birkhofer D, et al. Risk factors for lumbar disc degeneration. Spine 2002;27:125-134.
16. Prandini MN, Herculano MA, Paes N, et al. Lombalgias crônicas: quando operar. Rev Bras Neurol 2002;38:26-32.

17. Gibson JNA, Grant IC, Waddell G. The Cochrane review of surgery for lumbar disc prolapse and degenerative lumbar spondylosis. Spine 1999; 24:1820-1832

18. Carey TS, Evans AT, Hadler NM, et al. Acute severe low back pain: a population-based study of prevalence and care-seeking. Spine 1996;21: 339-344.

19. Fritsch EW, Heisel J, Rupp S. The failed back surgery syndrome: reasons, intraoperative findings and long-term results: a report of $182 \mathrm{op}$ erative treatments. Spine 1996;21:626-633.

20. Radu AS. Síndrome pós-laminectomia e fibrose epidural. Rev Bras Reumatol 2000;40:137-148.

21. van der Giezen AM, Bouter LM, Nijhuis FJN. Prediction of return-towork of low-back pain patients sicklisted for 3-4 months. Pain 2000;87: 285-294.

22. Kraemer R, Wild A, Haak H, et al. Classification and management of early complications in open lumbar microdiscectomy. Eur Spine J 2003, 12:239-246.

23. Ross JS, Robertson JT, Frederickson RCA, et al. Association between peridural scar and recurrent radicular pain after lumbar discectomy: magnetic resonance evaluation. Neurosurgery 1996;38:855-863.

24. Vogelsand JP, Finkernstaedt M, Vogelsand M, et al. Recurrent pain after lumbar discectomy: the diagnostic value of peridural scar on MRI Eur Spine J 1999;8:475-479.

25. Osterman H, Sund R, Seitsalo S, Keskimaki I. Risk of multiple reoperations after lumbar discectomy: a population based study. Spine 2003;28: 621-627.

26. Swartz KR, Trost GR. Recurrent lumbar disc herniation. Neurosurg Focus 2003;15:1-4

27. Graver V, Ljunggren AE, Loeb M, et al. Background variables (medical history, anthropometric and biological factors) in relation to the outcome of lumbar disc surgery. Scand J Rehabil Med 1998;30:221-225.

28. Byrns G, Agnew J, Curbow B. Attributions, stress and work-related low back pain. Appl Occup Environ Hyg 2002;17:752-764.

29. Carroll LJ, Cassidy JD, Côté P. Depression as a risk factor for onset of an episode of troublesome neck and low back pain. Pain 2004;107:134-139.

30. Currie SR, Wang JL. Chronic back pain and major depression in the general Canadian population. Pain 2004;107:54-60.

31. Levy HI, Hanscom B, Boden SC. Three-question depression screener used for lumbar disc herniations and spinal stenosis. Spine 2002;27: 1232-1237.

32. Anema JR, Van der Giezen AM, Buijs PC, et al. Ineffective disability management by doctors is an obstacle for return-to-work: a cohort study on low back pain patients sicklisted for 3-4 months. Occup Environ Med 2002;59:729-733.

33. Hoogendoom WE, Bongers PM, de Vet HC, et al. High physical work load and low job satisfaction increase the risk of sickness absence due to low back pain: results of a prospective cohort study. Occup Environ Med 2002;59:323-328.

34. Latza U, Pfahlberg A, Gefeller O. Impact of repetitive manual materials handling and psychosocial work factors on the future prevalence of chronic low-back pain among construction workers. Scand J Work Environ Health 2002;28:314-323.

35. Papageorgiou AC, Macfarlane GJ, Thomas E, et al. Psychosocial factors in the workplace: do they predict new episodes of low back pain? Spine 1997;22:1137-1142.

36. Schade V, Semmer N, Main CJ, et al. The impact of clinical, morphological, psychosocial and work-related factors on the outcome of lumbar discectomy. Pain 1999;80:239-249.

37. Hildebrandt J, Pfingsten M, Saur P, et al. Prediction of success from a multidisciplinary treatment program for chronic low back pain. Spine 1997;22:990-1001.

38. Pransky G, Gatchel R, Linton SJ, Loisel P. Improving return to work research. J Occup Rehabil 2005;15:453-457.

39. Hiebert R, Skovron ML, Nordin M, Crane M. Work restrictions and outcome of nonspecific low back pain. Spine 2003;28:722-728.

40. Okurowski L, Pransky G, Webster B, et al. Prediction of prolonged work disability in occupational low-back pain based on nurse case management data. J Occup Environ Med 2003;45:763-770.

41. Greve JMP. Etiopatogenia das dores lombares crônicas. Acta Ortop Bras 1998;6:180-186.

42. Graver V, Haaland AK, Magnaes B, et al. Seven-year clinical follow-up after lumbar disc surgery: results and predictors of outcome. Br J Neurosurg 1999;13:178-184. 